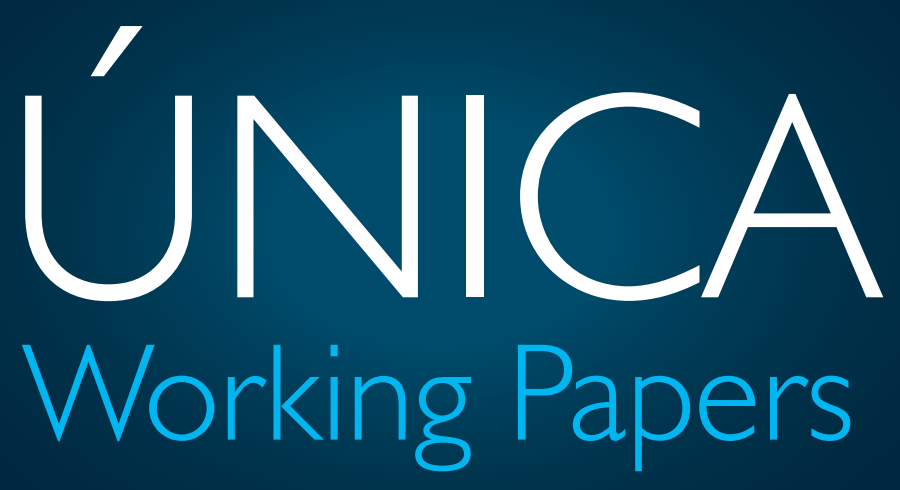

\title{
THE REST OF THE SCHOOL
}

The Group Director and Educating for Peace

- maRY ANNE MC DANEL DE GARCÍA

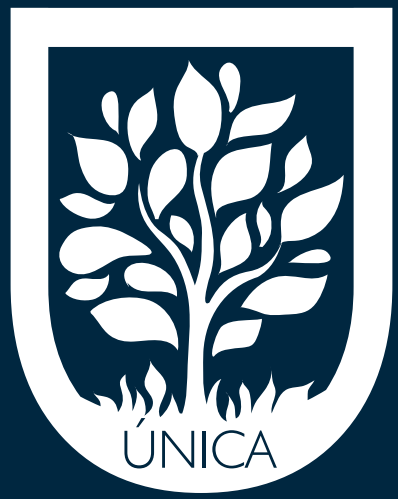

www.unica.edu.co 


\title{
THE REST OF THE SCHOOL \\ The Group Director and Educating for Peace
}

working paper 2

\author{
Mary Anne Mc Danel de García
}

\section{ÚNICA}

Institución Universitaria

Colombo Americana 
Facultad de Educación

Programa de Licenciatura en Bilingüismo con Énfasis en Español e Inglés

Bogotá D.C.

2018

Reg. SNIES: 106242

Vigilada MinEducación

Working Paper - Resultado de Investigación

Grupo de Investigación Innovation on Bilingual Education - INNOBED Categoría B Colciencias

Dirección de Investigaciones

Calle 19 No. 2a-49, Piso 3

Centro Colombo Americano

Teléfono: 2811777 Ext. 1291

dir.investigaciones@unica.edu.co

DOI: https://doi.org/10.26817/paper.05

Prohibida la reproducción parcial o total de esta obra sin autorización de la Institución Universitaria Colombo Americana - ÚNICA 


\section{Content:}

$\begin{array}{ll}\text { Acknowledgements } & \text { page } 3\end{array}$

Abstract and Key Words $\quad$ page 4

$\begin{array}{ll}\text { Introduction } & \text { page } 5\end{array}$

$\begin{array}{ll}\text { Education for Peace } & \text { page } 7\end{array}$

Uneasiness about being a Group Director page 8

$\begin{array}{ll}\text { Students share their experience } & \text { page } 11\end{array}$

$\begin{array}{ll}\text { What the job entails } & \text { page } 13\end{array}$

$\begin{array}{ll}\text { Managing discipline } & \text { page } 16\end{array}$

$\begin{array}{ll}\text { The Group Director } & \text { page } 18\end{array}$

Conditions for Successful Group Directors (form tutors, advisors) page 20

$\begin{array}{lr}\text { The Job Itself } & \text { page } 24\end{array}$

$\begin{array}{lr}\text { Findings } & \text { page } 27\end{array}$

$\begin{array}{ll}\text { Conclusion: } & \text { page } 28\end{array}$

$\begin{array}{ll}\text { References } & \text { page } 30\end{array}$ 


\section{Acknowledgements}

My gratitude to Juliana Roth Ordonez, PhD, MA, teacher, group director and language coordinator, whose dedication to the teaching of the English Language has enriched the lives of thousands of young people and to Terry Finnin, MA Education and Counseling, 47 years in education as teacher advisor and counselor, who generously gave of their time and vast expertise to carry out the evaluation and approval of this document.

Special thanks to my focus group, Maria de Lugo, Maria Clara Janer, Maria Claudia Arboleda, Maria Victoria Palacios and Elizabeth de Acosta for sharing their immense experience and expertise as Group Directors and coordinators of Personal and Social Education.

Thanks to Professor Carlos Arias for his testimony concerning the positive intervention of the form tutor in charge of his daughter at her new school; to Dominik Lehmann, age 14, who was very helpful in sharing his experience after transferring to a new school in grade 8, and Ariana Parra, age 9, who spoke of two form tutors and her experience as a foreign student and as a student returning to this country. Also thanks to Daniela and Lucia Hoyos, ages 17 and 14, who shared their perceptions of the advisory system employed at their school.

Thanks to my students from Administration in Education II and Professional Ethics for filling out the questionnaires concerning their perspectives about becoming form tutors. 


\begin{abstract}
Most teachers will eventually be assigned as group director (form tutor) for a group of students and will be responsible for monitoring their academic progress and their personal and social development of responsibility, leadership, cooperation, self-direction, and social, physical, emotional and creative values for success as positive members of society. This paper, based upon investigation, consult with eighth and ninth semester students of the Institución Universitaria Colombo Americana, expert group directors and coordinators of personal and social education, secondary school students, and the author's personal experience, indicates that the role of group director (form tutor or advisor) is primarily centered on academic achievement, and less upon covering the personal and social needs of the individuals. Students suffering adverse circumstances are especially vulnerable. The role of group director, while valuable anywhere, is especially so in Colombia, a country striving to "educate for peace" after more than 50 years of civil conflict. This document provides a condensed overview of the responsibility of the group director and its value in this process.
\end{abstract}

\title{
Key Words
}

group director, educating for peace 
"I believe that the school is primarily a social institution. Education being a social process, the school is simply that form of community life in which all those agencies are concentrated that will be most effective in bringing the child to share in the inherited resources of the race, and to use his own powers for social ends."

John Dewey (1897) My Pedagogic Creed, Article 2

"(translation) One of the relevant elements of an educational project in a school is the formative component and the safe keeping of the students, which normally is developed or implemented by the educators who carry out the function of group director."

José Guillermo Martínez Rojas (2018) Manual del director de grupo, p.15

\section{Introduction}

The individual student has many needs which go beyond the actual learning of academic subjects. The happiness and eventual success of the child depends greatly on how he/she feels about the school and his/her place in it. This goes far beyond the classroom and encompasses the entire school experience. Each individual should have the opportunity to discover and develop special interests and talents. The physical, emotional, intellectual, and social aspects of their personal development are as important as the academic factors which often flourish or decrease depending on the others. John Dewey got this right, as well as a lot of other things that we, in this virtual age, are rediscovering and renaming. These nonacademic aspects not only enrich learning but also construct positive citizenship and stimulate attitudes toward learning which will in turn guarantee success academically. The pastoral aspect is an area that most teachers in formation are not made aware of in their formal studies. This includes the role of the group director, its many functions and the immense importance of the job. Anything student oriented or student produced that is outside the realm of the classroom and study of particular subjects is in the realm of student life. These include social interaction participating in extra-curricular activities, sports programs, clubs, excursions, publications, or special events. These are often the child's most cherished memories of his/her school experience, as they allow him/her to explore and develop special interests and talents. The group director is fundamental in helping the child develop interpersonal skills as well as identify and develop talents, and fully enjoy the whole school experience. 
The group director is the teacher assigned to monitor and intervene in the whole experience of the children in a group assigned to him/her. The position is known by form tutor, advisor and group director, but for the purpose of this document we will refer to the group director. This special teacher not only monitors the academic progress of the children but also is fundamental in the personal and social growth and development of the individuals and the group. John Dewey (1897) emphasized what he felt is the primary part of the teacher's job, "I believe, finally, that the teacher is engaged, not simply in the training of individuals, but in the formation of the proper social life." (p.11) This idea is also expressed by Narvaez (2008), "Teachers mold certain forms of social life within classrooms, and influence students' experience of community and school membership." However, according to this investigation, it seems that the main emphasis is no longer there, but on academic achievement. Today, teachers are under extreme pressure to get high academic results on external exams which embellish the prestige of the school. Educating the whole child to become a positive element in the social context has been pushed aside as teachers struggle to maintain high results, even if it means teaching to the test. Teacher evaluations emphasize student's test scores. As I have mentioned in another publication, according to the Center on Educational Policy at George Washington University, Graduate School of Education and Human Development (2016) "Among the teachers who received performance evaluation in 2014-15, 54\% said student test scores were among the evaluation criteria." This accounts for the fact that it is increasingly difficult to encourage teachers to take on the responsibility of being a form tutor. It may even become difficult to get them to remain teachers! The responsibility of pastoral care is simplified for the teacher, but perhaps more complicated for the student. This investigation indicates that the time designated to group direction is generally not as productive as one would hope. The teachers are not guided or prepared in any way to do a better job. Some however use their own initiative and are outstanding in their endeavors.

The experience of the "home room" in the hands of a group director is intended to offer the best possible co-existence for each child and to result in the maintenance of high student morale and an effective positive climate, which will be manifest in learning. It offers the opportunities for children to develop special talents, learn from mistakes, and be both personally and socially able to contribute positively to their community. In the long run the effort will result in a positive culture for society in general. In compliance with the Colombian government's goal to "educate for peace", this paper proposes to provide teachers in formation with an overall view of the importance of the group director in student life and offer basic orientation as to what their participation in the role might entail. For this purpose, information gathered from a focus group of prominent figures in Personal and Social Education with years of experience as group directors, interviews with secondary school students, questionnaires applied to eighth and ninth semester teachers in formation, and personal experience will be incorporated. 


\section{Educating for Peace:}

In Colombia, after more than 50 years of civil war and the imperative need to bring it to an end, there is an urgency to educate for peace. All teachers and particularly all group directors in all schools should be dedicated to this task as part of their daily activity. Marrazo (n.d.) reminds us that the factors which perpetrate negative aggressive behavior stem largely from negative experiences and concerns that produce fear. It is an understatement to say that a large portion of the Colombian population has suffered such experiences. The result is a feeling of emotional disconnection with others and the following symptoms result:

- "strong desire for self-fulfillment and immediate gratification at the expense of others.

- Need for emotional protection, accompanied by judgmental, blaming attitudes.

- A loss of meaning in life or a lack of positive identity.

- The use of power, fear, and intimidation in interpersonal interactions.

- Little sense of joining with others

- Hurtful, aggressive, violent behavior" (pp.3-4)

These are characteristic of a toxic culture that has been long in the making.

The Colombian Ministry of Education requires a component to be covered in courses of social studies and ethics and values. Law 1731 of 2015 constitutes "Education for Peace" as an independent subject and corresponds to the National Constitution, articles 22 and 41 which calls to "(translation) create and consolidate a space for learning, reflecting on, and discussing the culture of peace and sustainable development that continues to generate well-being, and the betterment of the quality of life for the people." (Educar Para la Paz, Ministerio de Education) Although this should be trans-disciplinary, the group director is a key factor in carrying out this important part of student formation. Arboleda et al. (2017) present six concepts based upon "A Holistic Framework for Peace Education" that are basic for educating for peace. These are: (translation)

- Educate to live with justice and compassion for others.

- Educate to promote Human Rights and responsibilities.

- Educate to construct a culture of respect, reconciliation and solidarity.

- Educate to live in harmony with the Earth.

- Educate to cultivate individuals who are at peace with themselves.

- Educate to dismantle the culture of war. (p. 20)

Marrazo enumerates the interpersonal skills that should be developed in our young people in order to counteract the aforementioned symptoms of emotional disconnection that impede a peaceful resolution of a half century of civil war. These qualities are universal and 
applicable to every society, even the most peaceful. The personal and interpersonal skills that must be developed are:

- "responsible, thoughtful behavior

- increased self-respect and self-esteem

- respectful, honest relationships with others

- independence and interdependence

- a sense of emotional connectedness with oneself and others." (p.3)

With reference to the points listed by Marrazo and many others, Best (1990) points out a sad fact, "It is by no means certain that the development of these skills is high on the list of priorities of those who control our education systems, nor of those who plan our teachertraining courses." (p.21)

Very few people, other than family, have the time with the students or the interpersonal skills to stimulate these characteristics. This task logically falls upon group directors and other teachers. These are all skills that group directors should project in their interaction with their assigned group. It includes the way the school manages discipline, and it is vital in creating and maintaining a positive climate and culture.

The system of restorative practice, for example, along with Due Process (Debido Proceso) is far more educational than the punishment for offence system that is the traditional practice. We can go back to John Dewey (1897) for his opinion, "I believe that all reforms which rest simply upon the enactment of law, or the threatening of certain penalties, or upon changes in mechanical or outward arrangements, are transitory and futile." (p.10)

Group directors, and all teachers, are and will continue to be a vital factor in constructing and edifying a productive peaceful society. It is part of the job! Again Dewey, "I believe that education is the fundamental method of social progress and reform."... "I believe that education is a regulation of the process of coming to share in the social consciousness; and that the adjustment of individual activity on the basis of this social consciousness is the only sure method of social reconstruction." (p.10)

\section{Uneasiness about being a Group Director}

"Sometimes described as "the foundation stone of the pastoral system", it is the form tutor (group director) who is charged with day-to-day responsibility for the general well-being of a class of 24 to 30 youngsters."

Ron Best (1990, p.15), Pastoral Care in Schools: Some Implications for Teacher Training. Australian Journal of Teacher Education, 15(1).

Nearly all teachers are asked to take on a form group. Many times, this request is met with a definite "NO". Reasons I recall from my time as Head of Secondary School include, "I am 
not a babysitter. I don't feel comfortable talking about kid's problems. What would I do during the time I have to be with them with nothing to teach. I don't feel comfortable talking about drugs and sex. I have enough work just teaching my classes. No way, I would have to be in constant contact with their parents." And so it goes. None the less, most teachers do not escape the responsibility and assume it with no orientation. As Best (1990) so rightly states,

"Since almost all new teachers entering the profession will be form-tutors (group directors) by their second year in post and many probationers are given the role from the start it is reasonable to expect preparation for pastoral work to be an important part of initial training courses. The universal existence of pastoral bureaucracies and career ladders might be thought to entail a comparable provision of post-experience in (in service) training. This is hardly the case." (p.18)

Right, this IS hardly the case. Teachers in formation are not prepared for the pastoral part of teaching. However reasonable it may be that pastoral work be part of the training courses, nearly all emphasis during preparation is placed on pedagogical practice. Students come out ready to teach, but ill prepared to face the challenges of being a group director or helping a child in anything other than the academic. In a survey that Best and Mather (1984) carried out in England and Wales, they found that the teacher training faculties of colleges and universities were aware that there was a great lack of provision for the pastoral role of the form tutor. Best (1990) refers to that study and observes, "In initial teacher education, little seems to have changed. If anything, the criteria of the Council for Accreditation of Teacher Education (CATE) have further restricted the time available for considering pastoral roles."(p.19) He says that colleges and universities admit the weakness in their programs and chalk it up to not having enough time, or that these skills are "better learned on the shop floor." That would scare anybody. I fear that this is common in all countries and if anything is becoming worse. Best recognizes that we cannot expect teachers to be professional counsellors, but insists that they need to have observational skills, interpersonal skills, be good listeners, good reflectors, offer encouragement, and help children understand and seek to understand their problems, feelings, and attitudes. They must also be able to determine when a case needs more specialized help and be able to refer the child to the proper support. Narvaez \& Lapsley (2008) verify this, "In summary, teachers need content knowledge about the links between caring classrooms, achievement and prosocial character. Teachers need the pedagogical skills to pull it off; and they need the disposition to be committed to providing caring climates as a teaching practice." (p.3) In today's highly virtual world less and less human warmth is transmitted. Digital contact does not satisfactorily replace a direct personalized connection with another caring person. There is a deficit in the system which is largely concerned with academic achievement and success on standardized tests, although they do intervene in social and personal issues when alerted to them. Maria Claudia, a member of the focus group for this study and coordinator of a group of form tutors, is now a key member of a newly initiated advisory system at her 
school, and she informs us that most of the teachers involved do not have any training for this. (Focus group, December3, 2018) Quoting Ross McGill, an education blogger on Teacher Talk, Niemtus (2015) says that he sums up the preparedness of the vast majority of teachers to take on the responsibility of group director. "Good schools give you a bit of an introduction, but then it's usually no more than a couple of meetings on safeguarding, attendance and detentions. Otherwise the only training is watching other people do it when you're a trainee teacher. It is very haphazard." (p.1)

Haphazard? Sometimes what these trainee teachers observe is not very positive. Sergio, one of the ninth semester students in practice teaching, had this to say about the teacher who was directing his practice. He was concerned that the teacher either didn't really like the job of group director or just didn't have the preparation, "There are two points that I want to highlight when observing the group director that I have in my practice teaching. First, monotony. It may happen because of different reasons such as boredom or lack of interest and innovation. And lack of preparation."(Questionnaire, December 2018)

Exploring the perceptions of other students who answered a questionnaire, we can observe apprehension to assume the responsibility of group director due to feeling unprepared but also, and more importantly, a great desire to take it on. Seven students who are in their eighth semester of preparation for their teacher's license at the Institution Universitaria Colombo Americana UNICA responded to a questionnaire in September at the beginning of semester 2, 2018 that they had not received any training in how to manage pastoral care. Maria Alejandra answered, "Well, I haven't really had any information about how to handle pastoral aspects." Jader likewise states, "Not really. Most of the courses are focused on content and teaching skills - " All seven answered that they would have liked to have had preparation in this area. It can be argued that the same teaching skills required to teach any subject apply to pastoral aspects, and in part this is true, but mechanical teaching methodology does not cover the need for personalized understanding, concern and warmth.

In December, at the closing of the semester, after covering a small unit on guidance, these same students were asked again if they felt prepared to take on the responsibility of being a group director. All answered no. Nonetheless, all felt that they would try their best and learn from experience. Juan Esteban said, "We have to have at least a basic knowledge in guidance, so we could be prepared to help children who are isolated or who change their behavior. I feel I am not prepared but I will combine what I have learned with reality and learn from experience." Jessica Alejandra expressed that she would like to be a group director but felt apprehensive:

"I really like this side of guidance and everything related to helping people to deal with their emotions, their problems, and the find a way to preserve positive feelings. I could say that I would like to be a group director although I have to say that because 
of the lack of experience I would not be prepared for that yet. I really feel stressed about thinking about this level of responsibility."

Jader referred to the responsibility involved but was more positive than he had been at the beginning of the semester, "I don't think I have gotten to that level. Being the director of a group means to become a supporting hand for all your students, and I can be that support, but not as effective as it would be having the knowledge and the experience..." Daniela felt that having more experience would be good, "To be a group director carries many kinds of responsibilities like taking action when something happens. I will say that I don't really feel prepared to be a group director until being a teacher for a significant period of time." Laura showed her "can do" attitude, "I would say that being prepared is something mental, it is in your mind, but being open to learn and to confront situations is what will lead you to feel prepared. It is more about confidence and willingness to help." Charlie recognizes the importance of helping children overcome adverse circumstances first, and after that think about strategies to help with academic performance. He also identified the need for basic counseling strategies. "Teachers trained in basic counseling strategies can help children in adverse situations a lot." It says a great deal for these young teachers in formation that they may be frightened of the responsibility but are willing to do their best to take their place as school leaders by assuming the role of group director. It is evident that these students understand the importance of the role of group director perfectly well although they do not feel that they have been sufficiently prepared. Several of them indicated that they had not even had a group director at all in their schools. (Interviews with students, September and December 2018)

The Teachers Views and Voices, Center on Education Policy carried out a study in 2016 in which they found that the two most cited reasons for becoming teachers were "to make a difference in student's lives" and "to help students reach their full potential." (Figure 1-A, titled Most significant reasons why teachers joined the profession. P.14) None the less, most will not be able to fully accomplish this, either because they will have to focus on academic results only, or because they will not be given the chance in their schools.

\section{Students share their experience}

Group directors are great builders of self-confidence, social and emotional equilibrium, selfknowledge and team work. They are essential in discovering special talents and building responsibility. The group director not only encourages the students to participate in academic activities but also inspires good social skills and respect in all of his/her group. Several interviews were carried out with school children and university students that indicate the difference that a good group director can make.

Jader, when questioned, recalled two examples of teachers who had been concerned with the well-being of the students as well as their academic achievement. One was a Math 
teacher in grade eleven and the other a Spanish teacher during his primary studies. (Questionnaire, December 2018) The question is, two of how many?

A college professor and colleague shared his experience which clearly illustrates how important the group director can be. His daughter in grade six was withdrawn from the school she had always attended after the first semester of the school year because she was suffering severe bullying by her classmates. After much searching for the right school, she was admitted to a prestigious school here in Bogotá. Her group director along with the head of year and head of section provided a caring and careful process of orientation for her. She was assigned another student as a "guardian angel" that helped her get adjusted to her new surroundings. The group director, who was also the Spanish teacher, was fundamental in assuring a smooth and stress-free transition into her new school community. She was vigilant in monitoring the girl's personal and social adaptation as well as her academic process in catching up with the class. Happily, the girl successfully completed sixth grade and is thriving in her new school. The support given by her group director was vital in fostering her acceptance in her new school. This type of occurrence puts the teacher's empathy and creativity to the test. Parents and children alike approach these circumstances with great expectations and a large dose of fear. Parents want their child to adapt, be happy, and perform academically, and they will hold the group director responsible for their child's success or failure. (Interview, December 2018)

In another interview with a fourteen-year-old boy, Dominik, who just finished grade eight after transferring to another school, stated that he had been very well received by his new classmates because his group director, who was the Spanish teacher, was "muy chevere" (pretty cool). There were twenty-nine teens in his class and the teacher had fostered a positive climate and culture in the group which allowed him to not only integrate but also become quite popular. The group met every morning and on Wednesday afternoons for twenty minutes. The tutor helped resolve conflicts and other difficulties that the students had. Dominik affirmed that he was completely happy with his new school. (Interview, December 2018)

Ariana, nine years old, has had two challenging experiences adjusting to two new schools, one in the United States and one in Colombia. She returned to Colombia from the United States, where she had completed second grade and learned English. The group director in the US was accustomed to helping students from multinational backgrounds adjust to their new environment and become fluent in English. The teacher was diligent in monitoring the integration of new students and Ariana adjusted rapidly and happily. Upon her return to Colombia, given the command of English she had acquired during her time in the USA, her parents enrolled her in what was supposed to be a bilingual private school. They felt it would be better to repeat one semester of grade two because she had not learned the multiplication tables in the US, whereas her classmates in Colombia had already studied them. This choice would also benefit her by bringing her Spanish up to grade level. At her 
new school her level of English was superior to that of her classmates and that of her group director. The teacher taught all subjects to twenty-four students. This teacher took no action in solving some conflicts and stopping bullying that the girl was suffering from her classmates. The group director's attitude was that these were just "children's nonsense", and that the situation would solve itself. Both the child's and the parents' perception was that the teacher should have been more sensitive and proactive in the situation. Given the circumstances, their decision was to seek another school where a more adequate orientation and adaptation process would allow Ariana to make a smoother transition. (Interview, December, 2018)

These testimonies are only a small indicator of the difference that a good group director can make in the life of a child facing a stressful situation.

\section{What the job entails}

Martinez (2018), who has recently provided an excellent book in Spanish for the orientation of group directors called Manuel del Director de Grupo, outlines seven categories that require the daily attention of the group director. Although these seem quite obvious, it is worthwhile to enumerate them and briefly recall their significance and why it is important to have the direction and support of the group director. The first area is the social interaction of the child. This entails tolerance for differences, respect, solidarity, and responsibility for and with others and with their communities, and the development of each child's unique personality. A student's development of social skills and academic rigor will be reflected in his/her future work and contributions to an equitable peaceful society. The group director will support the child in resolving conflicts and personal adverse situations, and help develop skills in conflict resolution, anger management, effective communication skills, problem solving and leadership. "(translation) Many of these abilities and competencies construct the basic norms of courtesy that are required for social interaction, which are generally formed in the context of family and, in some way, the educational institution should contribute to their formation." (p.28)

Children are often confronted with situations that greatly affect them emotionally, sentimentally, in their self-esteem and how they relate to others. This is the second aspect mentioned by Martinez, and the most delicate task of the form tutor. The reasons for a child to become upset are so many that it would be impossible to list them all, but some of the most common are, physical abuse, parental divorce, illness or death of a loved one, bullying (verbal, cyber, physical), special educational needs (dyslexia, ADHD, dyscalculia etc.), nonacceptance by classmates, breakup with girl or boyfriend and so forth. This will often, but not always, become manifest in a drop in academic interest and achievement, misbehavior, and signs of withdrawal from interaction with others. In the case of misbehavior, the student is usually punished, but does not reveal what might really be bothering him/her, 
thus no solution is given to the cause. The group director is usually the first to detect this. In no way is he/she to take on the role of psychologist or counselor; teachers are not professionally prepared for that. Rather, "(translation)... in this dimension of their human development it is more a matter of knowing what the person might be dealing with, know how to give orientation in the basic aspects of their process of development, listen and give orientation in their search for professional help if it is required, among other things." p.29 To overcome an adverse circumstance, the student must feel that someone cares about them and will support them. We all do. Unfortunately, many will not receive the attention they need to be able to manage their emotions, self-image, self-esteem, sexual maturation, and build a project for life.

Martinez mentions a third and extremely important part of the educational process which is to prepare the student to be able to make responsible decisions taking into account the moral and ethical determinants of both the individual and the social context in which he/she finds him/herself. Responsible decision making is not an easy task for anyone. It becomes extremely difficult in adolescence when peer pressure and the desire to be accepted are at their highest point. For example, it is the unprepared teenager or pre-teen who will fall into drug use at the insistence of classmates or older students. Ethical and moral judgment must be nurtured as the child matures; this is a process that is often not complete until the individual reaches the early twenties. It is important for the group director to be informed of the stage of moral development his group is in according to Piaget and Kohlberg to be able to understand the level of maturity. This process entails assuming consequences for decisions both good and bad, respecting the established norms and knowing the reasons for them, and constructing personal values and principles which will conduct personal and social interaction for the benefit of the individual and the community. This is not a process of crime and punishment but rather a rational compliance with established accepted conduct respecting the liberty to evaluate and choose what is best for the individual and for the community. (p.30-31)

As a fourth aspect, Martinez reminds us that the formation of citizenship and political consciousness is indispensable for "educating for Peace." To be able to understand the situation of the country it is mandatory to know why and how it came about. Martinez gives us three areas that must be fortified. The first is historical consciousness. Students must be informed of how historical events have impacted the development of the present situations. Second, future adult citizens must have established values which include civic virtues, the identity of citizenship or sense of belonging, a sense of what is public and the care of it, and values of solidarity, justice, and tolerance for differences. And third, citizens must have a good capacity of judgment and political action which will allow careful deliberation and confrontation. (p.33) Each year, when the results of the Saber Pro exam of the universities are published it is depressing to observe the low nationwide scores in citizenship competencies (competencias ciudadanas). Clearly Colombian education is failing in this aspect. This indicates that the schools are not preparing students to be positive 
contributors to the common social good. Neither are the universities. The group director, along with other teachers, is vital in overcoming this deficit. Martinez refers to Ramirez (2003), "(translation)....professors can stimulate the formation of the political person seeking to develop a clear consciousness of social responsibility and participation, values that are promoted daily in school life." (p.33)

Learning is the reason for the existence of schools. It is why we teach, and it is the fifth area mentioned by Martinez. Anyone in education knows that they are there for the academics. In our enthusiasm, we teachers sometimes resort to the "open your mouth and shut your eyes" system as we spoon our vast knowledge of our subject into their not always anxious mouths. Sometimes it gives them indigestion and they cannot keep up. The group director knows that he/she is there for the children and must be informed of how each child is doing in his/her subject and in those of all the other subject teachers. Knowledge of each person's academic strengths and weaknesses, the objectives of the different subjects, and any difficulties that may arise between students and other teachers is indispensable. These concerns need to be communicated to parents as well, and suggestions for support should be offered. For example the group director may suggest that parents contact a tutor for a particular subject to bring the child up to grade level, or offer to go with a child to talk to a teacher the child has had a problem with. Martinez calls the group director a mediator (mediador) between what the institution seeks to achieve and the students who are in the process of formation. (p.34) To be able to give the best to students, teachers must participate in constant professional development. Teachers tend to forget that our students will need (or maybe not) what we can teach them, but also a myriad of additional abilities that have not yet have been invented. Education must strive for constant improvement and refocusing in the preparation of young people to assume the challenges of technology that changes daily. It is now common knowledge that in an article published by The Guardian, Perry (2016) warned that a study carried out by Oxford University found that $47 \%$ of existing jobs would disappear in the next 25 years. (p.1) How can we prepare them for that?

School life is not only about academics. Other areas of activity also provide formation for life, and this is the sixth area of interest. These are the many sports programs, competitions and recreational activities in the form of clubs and classes which develop special talents such as skating, music, art, swimming, cooking and many others. These are the activities that the children like the most, and in which they learn to play fair, share, socialize, and create. This provides a space where the teacher can really get to know the child in a relaxed and more spontaneous context. It does not mean that the teacher needs to be present during all the games or classes, but once in while it would be nice to look in. A compliment on the outcome of a game, an exhibition, or how well he/she did in a performance does wonders to motivate a discouraged student, or anyone else for that matter. Parents are also very pleased to hear that the group director knows what their son or daughter is doing outside of class. (pp. 35,36) 
Finally, the seventh and most common area of intervention has to do with special problems and conflicts that arise daily in any school. Most of them are routinely solved, such as strong disagreements, petty bullying, sickness, accidents etc., but others are far more serious. There is no ordinary day in a school. We have mentioned some of these elsewhere, but they include suicidal tendencies, substance abuse, severe bullying, delinquent activity, hacking, vicious rumors, physical fights, complex family situations, sexual abuse, unwanted pregnancies, stealing and so forth. These may require the referral to medical or psychological support. It is important that the group director is informed of these situations and provides support without getting involved in the private affairs of the students. The management of parental encounters can be very delicate. There will often be negation, violent anger and blaming the teacher or the school. This will put all of the group director's communication abilities to the test. No one likes to hear that their son or daughter is in trouble. The group director should never attend one of these meeting alone. They should always be accompanied by the head of year, psychologist, counselor or even the Head of School if the situation requires. Martinez tells us:

"(translation) In these last eventualities, considering that they can give rise to very serious circumstances, the advisor or group director must know the protocol and institutional policies to be able to give the situation the stipulated management so that the student, his/her family, or the educational institution are not put at risk." (p.38)

The community handbook (manuel de convivencia) will contain the policies and procedures for this and for nearly everything else.

Martinez (2018) has identified the most important areas of attention that the job of group director covers. Therefore, it is of primary importance that teachers be informed and prepared to do the job.

\section{Managing discipline}

Another factor that greatly influences the entire student experience is the disciplinary procedure outlined in the respective community handbooks (manuel de convivencia). The group director must ensure that the norms of conduct and corresponding consequences are not only made available to the entire community but also understood regarding their reason to be and the formative intention of the process itself. The group director is nearly always involved in the disciplinary process and is always the first contact with the child and his/her parents, whether or not the problem occurred on the playground, in another teacher's class, in the group director's class, or at home. Strictly punitive measures do not always render the best results and often do little to educate the child. In fact, they sometimes lead to the destruction of the child, who continues in a negative pattern and 
may even finish expelled from the institution of simply drop out. In Colombia, due process (debido proceso) must be followed. Martinez (2018) reminds us that the dignity of the individual must be protected and his/her rights conserved. He gives a very comprehensive guide on how to follow this process here in Colombia, and how to apply the procedure outlined in the community handbook (manuel de convivencia). He indicates several factors that must be taken into account when carrying out a disciplinary process. These include the age of the child who commits the fault, the context in which it occurred, the personal and family circumstances of the student, the existence or nonexistence of prevention measurements, the effects that the imposition of the consequence may have on the educational process of the child, and the obligation of the State to guarantee the educational process of the child or adolescent. (pp. 57-58) The group director is an important figure in this process, and should be versed in the procedure required, and prepared to submit the corresponding information mentioned above. As Martinez affirms:

"(translation) During school life, students tend to get involved in situations that, if not managed adequately, can degenerate in problems that, depending on concrete circumstances and the improper management of emotions, could result in serious consequences. In these cases, the work of the companion or group director is important. Therefore he/she should possess sufficient good judgment and discernment to be able to handle these situations, always seeking to be impartial and a mediator who will conduct the involved parties to assume a position, resolve it properly and finally assume the consequences of their decision." (p.37)

Restorative Practice is being applied by many schools as a fair system that does not attack the dignity of the individuals involved. In Colombia's particular need to "Educate for Peace", this procedure is highly recommendable, and it can be argued that group directors should be educated in restorative practice through professional development in order to be able to educate their students for peace. Restorative practice is based upon the following goals:

- "The importance of fostering social relationships in a school community of mutual engagement.

- A focus on responsibility and accountability for one's own actions.

- Fairness.

- Commitment to equitable process.

- Active involvement of everyone in school with decisions about their own lives.

- Issues of conflict and difficulty are returned to participants, rather than making the behavior pathologies.

- A willingness to create opportunities for reflective change in pupils and staff."

Kane el al, 2007; Can Restorative practices in schools make a difference; Educational Review; vol.60; N.4;

Nov.2008, retrieved from //schools.cms.k12.nc.us/ridgeroadms/document.in September 2015 
The importance of expressing feelings and getting the whole story is stressed by Costello, Wachtel and Wachtel (2009). Students and teachers generally have no idea of the impact their words and actions have on others. When they realize this, they are more likely to want to try to make things better. "We should strive to express both pleasant and unpleasant feelings. We have repeatedly found that many students are completely unaware of the impact -positive and negative-- that their behavior has on others." (p.13)

The group director is a determinate factor in making the disciplinary process of a negative event into a positive educational tool. This is a valuable component in "Educating for Peace" in Colombia, or anywhere else.

\section{The Group Director}

Best (1990) explains that, "However, since personal and social development entails processes which are (by definition) "personal and social, in a way which (for example) Physics does not, the pastoral curriculum will require a distinctive pedagogy."(p.20)

Ideally, students are grouped with approximately twenty to twenty-five children in each group. That is if they are lucky. Many schools in Colombia, mostly public, have as many as forty of even fifty students in a group. In large schools there could be as many as four or five groups of any grade level of students. This would implicate from fifty to fifty-five teachers in the role of group director. These are in charge of monitoring the personal, social and academic progress of each child in the group throughout the school year. Among the group directors there is usually a level coordinator who heads the group for each grade.

The group director is the first contact that the students encounter each morning. They set the atmosphere and the tone for the rest of the day. If children are met with a smile and a cordial "good morning", they may forget something troublesome that they are bringing with them from home. Hedger (2016) puts it like this,

"A Form Tutor's role is central in both caring for students and, crucially, monitoring their progress both academically and socially; encouraging involvement, commitment, and high standards of work and behavior. The Form Tutor should be active in looking after the interests of the "whole child." (p.1)

Martinez (2018) emphasizes the social dimension which includes living among and with others and allows them to construct and participate in healthy coexistence.(p.24) The integral development of the child will depend greatly on a positive climate and culture of the classroom, created and maintained by the form tutor.

Darling Hammond (2010) stresses the importance of the "advisory systems" commenting on how the teacher works closely with their small group of students, during specified times during the week. They provide support academically and personally with the aim of 
guaranteeing success for each child. They maintain a close connection with families and not only discuss behavior and academic progress but also celebrate success. This can and will make all the difference for a struggling child.

"In these high-performing schools, teachers have an advisory group of 15 to 25 students who meet with them several times a week and, in most cases, stay with them for 2 to 4 years. The advisor (group director) works closely with the student, the family, and with other teachers to ensure that the academic and personal supports needed for success are available. Advisors meet with parents or family members several times a year to review student work, call home if students are absent or have difficulties---and to celebrate successes---and are available to parents who need to discuss family and student problems and needs." (p.246-7)

In a focus group composed of 6 experienced group directors and coordinators of Personal and Social Education carried out in November of 2018, the present coordinator of the "mentors" of the system, Maria Claudia, made several observations. She thought that the work-load for the mentors was entirely excessive because they also have to teach their academic subjects and participate in other activities as well. All other teachers on staff are dedicated only to teaching their subjects.

Some sessions of personal and social development are being carried out in mixed groups of students from sixth to eleventh grade. This would not seem to be the most adequate organization because, the personal and social orientation needs of sixth graders are not the same as those of grades eight or ten, nor do their levels of maturity coincide. All six members of the focus group were apprehensive that this would not be able to cover the needs of all students. They felt that there will always be students who are not noticed and referred and will not receive the support they need. (Focus group, December 2018)

Two teenaged girls, 14 and 17 offered their observations on the system used at an American type school in Bogotá. Entrance to school is monitored by taking a fingerprint at the main gate of the school. Students meet with advisors for 25 minutes and use the time to plan social projects or just study. Lucia, grade 9, explained that they meet with their "advisor" four days a week and have an elective activity on the fifth day. She expressed her concern that the teacher didn't really plan much for the sessions. "During the time in "Focus Group" we usually just talk to friends unless we have a test or homework to finish. The teacher doesn't take it seriously." Daniela commented that they take a lot of surveys about substance abuse and bullying, and these are quantitative not qualitative. There is a system called "Stand by Your Friends", and if a student is worried about another student for some reason they can tell one of a group of teachers who will contact that student, and investigate the concern. She said, "Not very many people use the system, because they don't want to be called a snitch (sapo), but when someone does use it, it works." (Interview, 
November 22, 2018) She mentioned that sometimes they ask a person to take a drug test, not as a punishment but as a follow-up.

Both agreed that more attention was placed on getting academic results than on personal matters. Daniela mentioned that there were 5 teachers for sexual guidance (SGDA) The home room system with group directors at that school goes up to grade 6 , after that it is the Advisory system for middle and high school. Both girls felt that there was not always enough attention given the personal situations of the students. Lucia recalled a case in the last school year where a girl's mother had died and no one found out about it until later. The girl was new at school and had few friends. She also shared a personal experience where the group director could have been more helpful. "A couple of months ago I was really upset about something that had happened, and I couldn't help crying. I asked the teacher if I could go out to the bathroom for a few minutes to calm down. She said in an angry voice, "No, just sit down and do your work." "I felt really bad." (interview, December 4,2018 ) As a point of curiosity, both girls agreed that the best teachers to talk to are the Spanish and Social Studies (Sociales) teachers, in other words the Colombian teachers at her school.

\section{Conditions for Successful Group Directors (Form Tutors or Advisors):}

There are certain conditions that favor the success of the group director that the school must take into considerations. The following, with which I heartily agree, are all mentioned by The Effective Form Tutor (February 11, 2016), and by Diaz (2009), and Martinez (2018), Manwaring (2018), and the focus group (2018).

- Sufficient time to realize the job successfully is a primary need. The teacher's schedule should have enough free time to attend both the students and the parents, as well as liaise with fellow teachers. In some schools it is compensated with less contact time in class hours. Time is always an issue for teachers and a couple of hours less of class contact can be an enormous advantage for planning parental conferences or seeking information about a particular child.

- The group director should have close contact with their level coordinator, the other teachers who have class with their group, and the secretary of the section they work in, as well as the school registrar, school nurse, and psychologist. This liaison is extremely important. They should be able to access the personal folders of their students under the prescribed regulations and terms of confidentiality. This allows a heads up when identifying problems of behavior or academic lapses. Schools should work time into the schedules of the teachers so that they can meet regularly. 
- The group director is primarily a role model for the group. He/she will set the standard for appearance (checking that students make proper use of the school uniform or that students are clean and neatly dressed if no uniform is required). Educators will affirm that insisting on a proper, clean, neat appearance is extremely useful in keeping good discipline because insisting upon complying with the rules of appearance sets the standard for complying with the rest of the rules. Punctuality is also of great importance. If the teacher is on time the students will also be on time, and this will become habitual. Good organizational skills are also modeled; thus, students learn to come prepared with all of the materials they need for their classes.

- The group director instills a sense of safety in the students. They should be the first person the child seeks for help and advice. The children know that if anything goes wrong they have a responsible adult authority that will stand by them and help them through it. Children need to feel they are not alone. (We all do.) Manwaring (2018) says that the group director is sort of a lawyer. "If a student has a rough time or is going through something difficult, then you need to advise other staff on how to treat them and work with them." (p.1) There was a sad case that illustrates this. There were two children, a boy in grade 6 and a girl in grade 3 whose parents had been through an ugly divorce. The father was awarded custody of the children and would not allow the mother to see them. The mother would stand at the fence of the playground at recess time to see if she could talk to the children. They would stick their fingers through the wires of the fence to try to touch each other for a few minutes. When the children's group directors realized what was happening they interceded with the principal to allow the mother to enter the main gate and spend a few minutes talking to her children. As the father was afraid that the mother would try to take the children away with her, the group directors gave up their own recess time to escort the children during the visit. This finally ended in a law suit that conceded the mother's right to have scheduled visiting time with her children. If it had not been for the intervention of the group directors, it would be difficult to imagine how this would have ended. (personal experience)

- The group director demonstrates fairness in dealing with problems among students. They are the mediator who is consistent, respectful and objective. This is not always easy, especially when you know who the guilty party is. However all parties must be heard with the same objectivity and respect. The offended child needs to be heard, but likewise, the offender also needs to be heard. This is often ignored and the child is left with low self-esteem and the sensation that he/she is not worth the attention of those in authority. 
- Being a good listener is fundamental. When a child comes with a problem, you never know if the problem is trivial of catastrophic, but you must listen with patience and objectivity whether it requires taking it to the principal or is so trivial that you feel like you are being stoned with popcorn. This can be very annoying when you are under pressure to get to class or need to do something else in a rush. Remember that it is important to the child or he/she would not be telling you about it. Somehow make time. If you really cannot listen right then, make an appointment for later or ask a colleague to fill in for you for a few minutes.

- It is vital to be an optimist. This goes for all teachers and school administrators. Encouragement and a sense that the teacher believes in the group or the individual is of upmost importance. Martinez (2018) refers to this:

" ( translation) One of the factors that generates important problems for the construction of an adequate atmosphere for learning has to do with the perceptions that the students have of their teachers and the way that these are generated in the classroom. It is common to hear them say, "... this teacher doesn't like me "or "for this teacher, I don't exist..." (P.129)

I recall a situation with a grade eight group that had several problems. Of the twenty-five students in the class, three had ADHD, and there were two groups of girls who didn't get along. The atmosphere in the group was tense, and about half of them just tried to keep a low profile. Their group director and all the subject teachers complained about having to "try" to teach them and about their academic level and bad attitude. The group director constantly chided them and told them that they were lazy and lacked intelligence and discipline. He constantly compared them to the other eighth grade groups and asked why they couldn't be like them. I was Head of Secondary at the time and one day three of the girls came to my office crying. They felt terrible about their group and said that none of teachers wanted to teach them. They felt stigmatized. They assured me that there were some good kids who wanted to learn, but the whole group was constantly put down by their teachers. Even some of the parents had begun to complain. This ended in a meeting with their teachers where they were made aware of the damage they were causing. The group director got a good "talking to" and realized that he had let the situation develop without intervention, or any effort on his part to try to help his group. The subject teachers spoke with the group, apologized, and gave them an injection of motivation. This change in the attitude of the teachers worked a miracle. The group settled down and finished the year with better academic results, a much-improved attitude, and good discipline. The group director was not assigned this responsibility for the next school year and the reason for this was consigned in his folder. This also affected his salary because the responsibility had a monetary benefit. (Personal experience) 
- Keep up with the news. Being able to talk to students about current events allows them to be aware of the world around them and to discuss, analyze and give objective opinions based upon facts. Here I am not referring to the bombardment of junk news (private life of soccer stars and singers, or the actress who wore a mini bikini on a yacht date), but to current events that affect them, their habitat, or the well-being of the world and people in general. They will learn that their point of view is important, and they have the right to be heard. They will also learn to value their position as contributing members of society.

- Be ready for the responsibility. Teachers should be consulted prior to being named for the job. If they are not comfortable they will not comply with all that is required of them. I have observed teachers who take the responsibility as part of their contract but have no desire or the know-how to be successful. This can be detrimental to the good functioning of the system and most important vulnerable children may not receive the attention they need. Sadly, I have seen cases where the children actually fill in for their form tutor. One day I asked one third grade boy why he was in the office so early, and he said, "I have to take attendance because Mr... is always late on Mondays." Twenty-five kids were in the hands of an eightyear-old!! Another incident was that of a six year old girl who conducted a crying classmate to the nurse. The classmate had fallen and hit her head on a desk top during home room. The girl had a bleeding gash on her forehead and the form tutor had not given it any importance. She told the girl to go to the bathroom and get some toilet paper to stop the bleeding. Her little friend volunteered to accompany her to the nurse. (personal experience)

- Diaz (2009, p.2) calls this charisma, but it is also diplomacy. The group director has to deal with parents, and some of them are angry! They also have to deal with rebellious children and obstinate colleagues. This requires intrapersonal and interpersonal skills, and self-control. It is a combination, neither unbendingly rigid nor permissive. It is a virtue to be prepared to lose once in a while and still smile. (A boss of mine once told me to learn to "smile and nod." It was good advice, don't forget it!) This has to do with diplomacy. You can think whatever you want, but it is usually better to abstain until you are ready to say it in a nice way. Also, give yourself a chance to find out all the facts before reacting. Sometimes things are not as they seemed at first.

- Good communicators get better results. To be a good communicator one must know the whole picture. If the group director knows his children, who their friends are, what they do well and what they have trouble with, he/she will not have trouble gaining their confidence. If there is trust, they will be open to talk. They 
must also know that their group director will not betray this. Professionalism requires keeping confidential information safe and getting needed support at a higher level. One case that comes to mind is that of a group of teachers who were talking in the staff room about a girl who was being physically mistreated by her father. They were using her name and describing the details of her injuries. How this child must have felt, not only abused at home but the topic of conversation at school? (personal experience)

- Another good skill to have is conflict resolution. All teachers in formation should be instructed in these techniques. Schools should provide professional development in this area as well, as teachers are constantly resolving differences that can include physical aggression, disrespectful heated discussion, and the silent treatment. Conflict not only can but does occur between students, groups of students, parents and children, teachers and children, teachers and teachers, teachers and parents, teachers and administration etc. I recall an incident where an outraged mother of a tenth-grade student actually chased the Head of the School (Rector) around the administration block shouting insults at the top of her voice! He repeatedly ask her to calm down and go into his office to converse, but to no avail. Finally, he was forced to call security and have her escorted out of the school. (personal observation)

All of the experts and persons consulted remind us that there is always more to learn. We don't have all the answers and we never will. We have gone from direct phone calls and personal meetings to WhatsApp and the school web mail. Our systems of communication are becoming more and more impersonal, and there is nothing we can do about it, so, keep up with it. Nonetheless, remember that confidential matters are better treated directly face to face. If a child has confided a personal situation or requires referral to the counselor or psychologist or the Head of the school, do it personally with the parents, and do it carefully. This is not a matter for WhatsApp or a chat group.

\section{The Job Itself:}

The task itself is quite complicated and requires a myriad of related and unrelated tasks, along with inter and intra-personal skills. Hedger, June (2016) Partnership Development Schools ( 2008-9), Diaz, H. (2009), and Martinez (2018) all enumerate and agree upon most of the basic roles that the group director must carry out. Along with these we have referred to a job description once used in a prestigious school here in Bogotá, but it is very similar in most schools. Here we will go over the points that are mentioned the most. Among these responsibilities are the following: 
- During that first contact in the morning the form tutor will take register and report it to the secretary of the section. He/she will carefully note absences or late arrivals. When a child is reported absent the secretary will call home to verify the reason for the child's absence, thus parents are notified in the case that they were unaware that the child had not gone to school. It seems that the early contact with the form tutor is a very important aspect in not only keeping records, but also in cutting down absences, as it creates a sense of providing a positive start to the day. Elhaggi, C.E. is cited in The Effective Form Tutor (2016) as she points out this important discovery,

"There appears to be a strong, significant and positive relationship between attendance at secondary schools in England and the role of the form tutor. In cases where the form tutor had a natural and constructive connection with their tutor group, the positive outcomes were evident in high levels of attendance." (p.1)

Here I must share another anecdote. One morning about an hour into the school day I received a call from the security team of a local shopping center. They informed me that three girls in school uniform were wandering around the mall and each had a bottle of beer. The first step was to ask the group director if the girls were in register. He said that a friend told him they were in school and had gone to their lockers to get a project they needed for their first class. He marked them present. Parents were summoned and a teacher and I went to get the girls. Needless to say they were surprised! This is an indicator of how important taking register can be.

- Know the students and keep their Student Profiles up to date. The group director will have access to these with the permission of the registrar. These are confidential and not to be shared with anyone else who is not authorized. Any information that is contained in this folder should be discussed with only those who need to know in order to benefit the child. The group director will record comments on academic progress and behavioral, health, personal, or family occurrences that may be necessary to understand in order to benefit the progress and well-being of the child. As the students move through the grades, each new group director will be informed of any particular situation regarding the students in the group.

- Group directors must be available for interviews with parents or caregivers whenever they are requested. These may be about student progress in academics and behavioral matters. It is one of the most important aspects of the job, and it is not easily planned because one never knows when something urgent may arise. Each parent interview or meeting should be recorded, specifying the main aspects discussed and any action to be taken. This includes but is not limited to being available at the times designated as "Open Days" or "Parent-teacher Conference 
Days" or meetings scheduled for giving parents information on the child's progress. All present in the meeting should read the minutes, sign and consign any observations they might have.

- The group director must liaise with teachers of other subjects, as well as the nurse and psychologist where necessary, and provide support for students who are suffering from adverse circumstances occurring in or outside of the classroom. The nurse in many cases is the prime source of information. Children will often consult with someone who does not represent authority when they are concerned with highly personal matters. The nurse is more accessible than the psychologist and it does not cause curiosity if they are observed by others. For example, frequent visits to the infirmary can indicate a health problem or avoidance of a particular class. The Librarian can also identify suspicious frequent visits.

- The group director is responsible for the supervision of his/her group in events organized by the school such as assemblies, bazars and special celebrations. Usually supervision is not the only responsibility. Primary group directors (form tutors) are frequently responsible for putting together an on-stage presentation for Mother's Day, Christmas and other special events. All group directors usually organize an event with their groups for bazars and other community and fund-raising events. This requires a great deal of creativity on the part of the group director. I might add that it also requires effective stress management skills and ingenuity. A key figure in the presentation always either gets sick or someone forgets to bring something important. Many years ago when I was teaching third grade, Scrooge in our Christmas play, did not arrive on the day of the presentation. His mother sent a note saying that the family was leaving on vacation early. Fortunately, Marley's Ghost knew most of the lines and we were able to make a quick change. Very stressful. (personal experience)

- Administrative information must be given to students, parents or caregivers. It is important that all of them are well informed of upcoming events, requirements and any information sent by the school director or head of section. In some schools a weekly bulletin is read to the students and sent to the parents. (They will probably forget anyway but keep trying.)

- When parental permission to participate in a field trip or another event is required, the form tutor is responsible for collecting these in writing and signed. This can be the biggest headache. (First the children forget to take the permission slip home, then they forget to have someone sign it, then they forget to bring it to school, then they forget to give it to the group director. (All of this takes place over about 5 days. 
Smile.) Oh yes, you cannot accept an electronic version, because it has to be a written signature to avoid falsification. As a last resort call the parents personally and ask them to please send written permission or the child will not be allowed to go with his/her classmates.

- School rules and policies must be clearly communicated and understood by all members of the community. The group director must ensure that these are followed and obeyed by his/her students. This information is consigned in the Community Handbook (Manual de Convivencia). This should be read and discussed with the form group at the beginning of the school year in group direction time, and revisited from time to time. As mentioned before, the group director will also be involved in any disciplinary process involving students from the group.

\section{Findings}

The concepts based upon "A Holistic Framework for Peace Education", that are presented by Arboleda et al (2017) are not new. In fact, they are very much in line with the twentyfirst century skills that teachers are implementing in the teaching of all subjects. These include critical thinking, problem solving, teamwork, and effective communication, interactive participation, investigation and application of findings to projects etc., and relating the topic to the reality and lives of the students. Faculties of education are teaching these principles in pedagogy classes. It is not difficult to see that these can be transferred to "educating for peace." The challenge now is to apply them to the responsibility of group directors striving to promote positive citizenship and social consciousness.

Many teachers are uncomfortable about being a group director or form tutor or advisor. They do not usually lack the desire to help, but they do lack the preparation. The investigation carried out by Best (1990) is conclusive, as were the results of the questionnaires and interviews carried out.

"The training of teachers has for too long taken pastoral care for granted, given it low priority or, worse, simply ignored it. If our expressions of commitment to the development and well-being of the "whole person" are to be more than empty rhetoric, this situation is in urgent need of correction." $(p, 21)$

Teachers are given very little if any preparation to enable them to become effective group directors. If Colombia is to "educate for peace", far more emphasis and training must be considered in the undergraduate programs and this will allow teachers to acquire the selfconfidence to take on the role. Practicing teachers must also be provided with professional development in this area. Students preparing to become teachers indicated that they had 
not received instruction or orientation about the role of group director. Professionals and students observed a lack of commitment in many of the group directors they had observed. In spite of this, students in teacher training at the Institution Universitaria Colombo Americana UNICA, are willing to take on the job and do their best.

It was interesting to note that four school children and a professor interviewed mentioned, without prompting, that the Spanish and Social Studies (Sociales) teachers were the best to talk to about concerns they might have. They felt that these showed more concern. Perhaps it has to do with the nature of the humanities, and the Latin American culture. (Interviews with school children ages 8, 14, 14, and 17 and the father of a girl age 12, December 2018)

Pastoral care in education is sometimes left aside by the need for schools to foment academic achievement, especially on standardized external exams. Educators are urged to "get results" at all cost, and sometimes their jobs depend on it. While educating for the rapidly changing future, and trying to provide a standard curriculum that will keep up with galloping technological advancement, we cannot allow the dehumanization of the individual. Students must not be allowed to perceive that their worth is based on their academic results alone. Awareness that there may be some underlying reasons for a student's lack of interest or achievement often depends upon the group director.

In "educating for peace", we must consider anger management, conflict resolution, restorative discipline, mutual respect, honesty, equity, empathy and strive to implement these in our educational procedures. The human qualities of each person must be cultivated and valued, and their self-esteem must be based on these. The challenge in this country, (and I dare say many others) is to gradually change a negative culture that has been in formation for more than half a century. Best tells us that personal and social development occurs through the personal and social processes of the experience of learning itself. "It can't all be taught, much of it must be experienced. Moreover, moral, political and ethical questions are intrinsic to both processes and content, so that teaching here is threatened with controversy at every turn." Unfortunately for many students in classrooms today their experience has not been positive. The group director along with subject teachers must be able to handle controversial discussions and organize meaningful group activities. (p.20) Sensitivity to the suffering and needs of others, respectful consideration of points of view, domination of the human urge to take revenge for harm done, and full understanding of causes and effects are only some of the aspects that need attention. Given the proper training and an adequate time allotment, the group director is already an institutionalized instrument of incalculable value for "education for peace."

\section{Conclusion}

We have seen that the position of group director requires an immense variety of human talents, not the least of which are empathy, patience, diplomacy, self-control and common 
sense. It is a big job! The tasks required are many and entail a multitude of bureaucratic functions as well as the patience of the holy Job. It also requires good humor. It is a combination of sales person, psychologist, philosopher, administrator, researcher, priest or minister, clown, environmentalist, nurse, police, detective, artist, musician, actor, friend, secretary and problem solver. Oh, I forgot expert in their field. Not all teachers are cut out for this. Therefore, these special teachers should be carefully selected and matched to groups of students according to their particular profile, and they should be allowed to freely accept the challenge.

In order to accomplish the Ministry of Education and government goal here in Colombia, a cross curriculum effort should be made. Topics of concern and formative investigation and discussion of citizenship should be touched upon in all subjects by all teachers in an interdisciplinary manner. Above all, these should be instilled by a caring adult role model who oversees the process of growth that allows each child to prepare to fortify a positive national culture of tolerance, conflict resolution, equity and respect. The traditional group director leads by example and should be a fundamental figure in this process. He/she must count with adequate preparation, programmed time to cover certain topics and the resources to facilitate the job. The very treatment the child receives during his/her school experience will be vital in how that child will approach a culture of peace and conciliation. Personal experience is more impacting than class discussions, readings and documentaries. Children must be enabled to resolve differences without violence. The role of group directors and other teachers that work with the children from the time they enter kinder until they graduate from secondary school will make an indelible mark.

The structure needed for "educating for peace" already exists in the system of group directors (form tutors, advisors). At the heart of this undertaking is the caring trustworthy adult who leads and teaches with his/her example. The academic progress, the personal, social and emotional needs of the children (and in some cases their families) need attention. The inconsistency of attention allotted students individually and the apparent lack of attention given formative and pastoral matters in academic classes, as well as insufficient preparation for the teachers must be attended to in order to meet this or any country's need to "educate for peace."

"I believe that every teacher should realize the dignity of his calling; that he is a social servant set apart for the maintenance of proper social order and the securing of the right social growth."

John Dewey,(1897), My Pedagogic Creed, (p.11) 


\section{References}

Arboleda, Z., Herrera, M.M., Prada, M.P. (2017). ARKD Consult S.A.S., Bogotá, Colombia. Retrieved from http://www.altocomisionadoparalapaz.gov.co/Documents/que-es-educar-y-formar-para-lapaz-y-como-hacerlo.pdf on November 22, 2017.

Best, R. (1990). Pastoral Care in Schools: Some Implications for Teacher Training. Australian Journal of Teacher Education. 15(1). Retrieved from https://ro.ecu.edu.au/cgi/viewcontent.cgi?referer=https://www.google.com/\&httpsredir=1\&articl e=1148\&context=ajte on October 2, 2018.

Castello, Wachtel and Wachtel (2009). The Restorative Practice Handbook. International Institute for Restorative Practices, P.O. Box 229, Bethlehem, PA 18016 USA.

Class Teaching, Find the Bright Spots. The Effective Form Tutor (February,11, 2016). Retrieved from https://classteaching.wordpress.com/2016/02/11/the-effective-form-tutor/ on Novevber6, 2018.

Darling-Hammond, L. (2010).The Flat World of Education. Teachers College Press, 1234 Amsterdam Avenue, New York, NY 10027.

Dewey, J. (1897). My Pedagogic Creed. School Journal vol.54 (January 1897). pp. 77-80. Retrieved from http://dewey.pragmatism.org/creed.htm on December 2, 2016.

Diaz, H. (I 12 octubre, 2009). Desafíos de la educación en el Siglo XXI: El tutor y su importancia en la formación integral del estudiante [Blog post] Educared. Retrieved from http://educared.fundaciontelefonica.com.pe/desafioseducacion/2009/10/12/el tutor y su impo rtancia en I/ on November 2, 2018.

[doc] The Role of the Form Tutor. Produced as part of the Partnership Development Schools (PDS). Strategy Phase 3 (2008-09). Lead PDS: The Park Community School. Retrieved from education.exeter.ac.uk/...\%20Role\%20of\%20the\%20Tutor/the\%...on October 29, 2018.

Kane el al, (2007). Can Restorative practices in schools make a difference; Educational

Review; vol.60; N.4; Nov.2008. Retrieved from

https://www.researchgate.net/publication/228364418_Can_restorative_practices_in _schools_make_a_difference on January 25,2019.

Martínez Rojas, J.G. (2018). Manual del director de grupo, Una guía para hacer efectivo el cuidado y la formación integral de los estudiantes. Cooperativa Editorial Magisterio, Diag. 36Bis, (Parkway La Soledad) No. 20-70, Bogotá, Colombia.

Manwaring, J. (2018). Teacher Toolkit, How to be an Effective Form Tutor. Retrieved from https://www.teachertoolkit.co.uk/2018/06/12/effective-form-tutor/ on November 13, 2018.

Marrazo, M.J.(201). Character Centered Teaching: Six Steps to Becoming a Model Program. Retrieved

from

http://www.arkansased.gov/public/userfiles/Learning Services/Curriculum\%20and\%20Instruction /Char\%20Cent\%20Teach/marraz 1.pdf on November 6, 2018. 
Narvaez, D. \& Lapsley, D. (2008). Teaching Moral Character, Two Strategies for Teacher Education. Center for Ethical Education, University of Notre Dame, Retrieved from http://www.tandfonline.com/doi/abs/10.../08878730701838983- on November 7, 2018.

Niemtus, Z. (2015). Six Basic Steps to Becoming a Brilliant Form Tutor, The Guardian, 15/1/20. Retrieved from https://www.theguardian.com/teacher-network/2015/aug/26/six-basic -stepsbrilliant-form-tutor on November 12, 2018.

Perry, P. (December 24, 2016). 47\% of Jobs Will Disappear in the Next 25 Years, According to Oxford Study. Big Think Edge, Retrieved from https://bigthink.com/philip-perry/47-of-jobs-in-the-next-25years-will-disappear-according-to-oxford-university on January 16, 2019. 